\title{
Concept Mapping as a Tool for Curriculum Design
}

\author{
Elizabeth McDaniel, Brenda Roth, and Michael Miller \\ National Defense University, Washington, DC, USA \\ mcdaniele@ndu.edu rothb@ndu.edu millerm@ndu.edu
}

\begin{abstract}
Concept mapping is typically used as a classroom tool for students to construct their own learning by illustrating the relationships and linkages among complicated concepts and their component parts. This paper reports on the application of concept mapping to create curricular schematics for academic programs that must be aligned to specific competencies. The competencies are mapped and represented in a visual framework to give administrators and faculty, as well as students, a better understanding of main ideas and how key concepts are integrated. Mapped representation of curriculum can be used to validate complicated curricula content and to assess student learning.
\end{abstract}

Keywords: concept mapping, teaching and learning, curriculum development, assessment, content management

\section{Introduction}

The authors of this paper are applying concept mapping as a tool for understanding, collaborating, validating, and integrating curriculum content that is designed to develop specific competencies in a graduate-level academic program. At the Information Resources Management (IRM) College, National Defense University (NDU), located at Ft McNair in Washington, DC, curriculum development presents unique challenges. Congress established the IRM College in 1988 to provide graduate-level education to Information Resources Management officials and leaders. In addition, the Secretary of Defense designated the IRM College to be the educational institution to implement the Clinger-Cohen Act (Information Technology Management Reform Act of 1995). Since the IRM College is funded by the DoD, the students are military and DoD civilians as well as senior leaders from other government agencies, foreign military officers and civilians, with a few private sector students from businesses who work with the government. Curriculum that has its foundations in congressional mandate and laws is complicated and must be monitored closely to satisfy high-level stakeholders as well as the needs of IRM students. Therefore, curriculum developers at the IRM College turned to curriculum mapping as a way to ensure we were addressing and validating competencies as well as integrating them across the College's four academic departments and five certificate programs.

Concept mapping, a tool originally developed to facilitate student learning by organizing key and supporting concepts into visual frameworks, can also facilitate communication among faculty and

Material published as part of this journal, either on-line or in print, is copyrighted by Informing Science. Permission to make digital or paper copy of part or all of these works for personal or classroom use is granted without fee provided that the copies are not made or distributed for profit or commercial advantage AND that copies 1) bear this notice in full and 2) give the full citation on the first page. It is permissible to abstract these works so long as credit is given. To copy in all other cases or to republish or to post on a server or to redistribute to lists requires specific permission from the publisher at Publisher@InformingScience.org administrators about curricular structures, complex cognitive frameworks, and competency-based learning outcomes. To validate the relationships among the competencies articulated by specialized accrediting agencies, certification boards, and professional associations, faculty may find the 
concept mapping tool beneficial in illustrating relationships among, approaches to, and compliance with competencies. The authors describe a specific application of concept mapping to curriculum and how curriculum mapping is useful to faculty and academic administrators charged with maintaining curriculum quality at the IRM College. They further suggest that curriculum mapping may also be useful for curriculum content management, an initiative in its early stages in higher education.

\section{Concept Mapping as a Tool for Learning}

Concept maps are graphical diagrams that can be used to organize knowledge in meaningful ways (Novak \& Gowin, 1984) and are generally attributed to Novak's early work examining children's understanding of scientific knowledge (1964) that resulted in the notion of graphical concept mapping. The concepts can be represented as either a circle or a box. The relationship among concepts is displayed using connecting lines. Clarifying words or symbols are typically associated with linking lines to explain the specific relationships among the concepts. Although concept maps are generally represented hierarchically (Novak, 1998), with the most general concepts at the top and more specific concepts arranged below, variations on this theme can take the form of chain, spider, and network formats (Hibberd, Jones, \& Morris, 2002; Ruiz-Primo \& Shavelson, 1996). Recently, Safayeni, Derbentseva, \& Canas (2003) suggested a cyclic structure would illustrate dynamic relationships and stimulate systems thinking more clearly. Researchers agree that the concept map format depends on the content and the individual using the tool. Figure One is a typical example of a concept map. It addresses a simple question, "What is a plant?" and illustrates how cross-links can be made and concepts organized. This is just one way the concepts listed on the left of the figure can be positioned in a hierarchical fashion to show relationships.

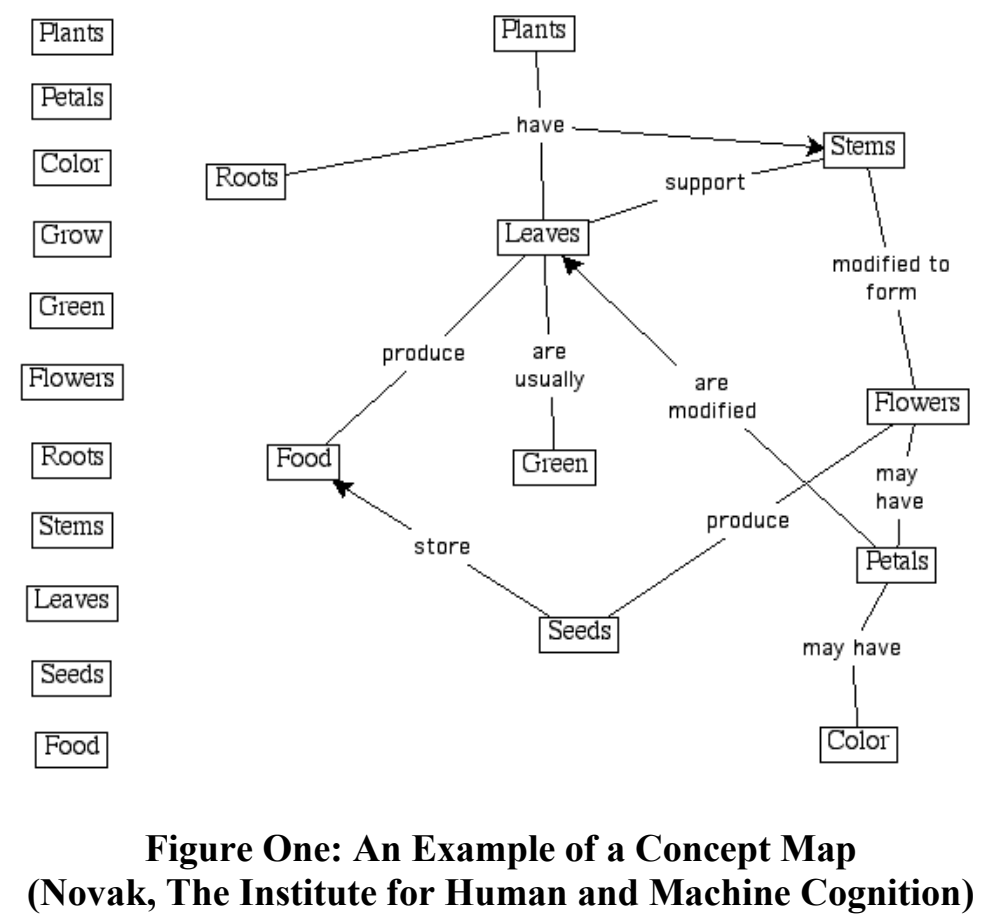

In addition to their role in representing knowledge, concept maps have also been pressed into service in support of initial learning. For example, Macnamara (1982) extended the view that new concepts are assimilated into existing frameworks (Ausubel, 1963, 1968) with evidence that children better understand the world by asking questions and seeing relationships among concepts. 
Researchers suggest that learning can be enhanced by hands-on activities in which learners actively identify the attributes of concepts. For example, Harpaz, Balik, and Ehrenfeld (2004) recently demonstrated the efficacy of concept mapping in encouraging students to think independently and to find connections among concepts. Concept maps are powerful tools for helping learners identify general concepts prior to instruction focused on more specific content, as well as an evaluation tool of the knowledge that is formed afterward (Mintzes, Wandersee, \& Novak, 2000; Novak and Gowin, 1984).

In much the same way concept mapping has moved from being a knowledge representation to becoming a tool actively used by students during learning, curriculum developers have deployed concept maps during the initial curricular planning process. For example, Edmondson (1995) used concept mapping to develop a problem-based veterinary curriculum. He found that using concept mapping principles in the curricular planning process resulted in course content being more accessible and easily integrated by students. Concept mapping also provides educators a more comprehensive understanding of what students need to learn and helps eliminate sequencing errors in the development of lesson plans (Martin, 1994). Similarly, the use of concept mapping in curriculum design is used for faculty development at the University of Tennessee at Chattanooga, which has a web site outlining the steps for making a concept map and provides a number of related references and resources (http://www.utc.edu/Administration/WalkerTeachingResourceCenter/FacultyDevelopment/Conce ptMapping/index.html ,1998). Review of the literature, however, reveals very few examples of how concept mapping is useful to link concepts for curriculum design.

Given the powerful role that concept mapping can play before, during, and after learning, we suggest it is a logical extension to consider concept mapping as a tool for curricular design and management, and for ensuring the systematic improvement in curricular quality.

\section{The Challenges of Maintaining Curriculum Quality}

Academic programs should be designed to facilitate learning that leads to intended learning outcomes. These outcomes are articulated by either faculty in the institution or by organizations external to the institution, such as specialized accrediting agencies or professional associations. Learning outcomes and curriculum content must be aligned at three points:

1). When a curriculum is first developed, its designers must articulate intended learning outcomes that align with competencies. Designers create a framework of educational experiences, to include courses and lessons, which facilitate learning leading to successful performance of the intended learning outcomes.

2). Once the curriculum is developed and delivered, it must be integrated within an academic program to maintain curricular coherence, and effective use of time and academic resources.

3). Once the curriculum has been developed and delivered, faculty must ensure it remains current with the intended learning outcomes and competencies articulated by the institution, the specialized accrediting agencies, and professional associations.

These curriculum development and validation processes are challenging because of the complexity of curricula, and the need to communicate clearly the links among competencies and curricular content. With education becoming increasingly more learning-outcome focused, curricula must ultimately lead to the desired performance of the learner, as well as to document a few of the added values of the educational experience. The learner's new knowledge and skills must be demonstrated using meaningful and authentic assessments of the intended learning outcomes. The use of concept mapping for curricular design and management is the focus of this paper. At the IRM College, we are in the early stages of mapping our entire curriculum to allow us to see con- 
nections immediately for greater coherence across the curriculum and to answer our stakeholders' questions about specific competencies.

\section{Mapping Curricular Concepts}

We are currently using concept mapping at the National Defense University's Information Resource Management College as a tool for designing our curriculum and for maintaining academic programs that meet articulated competencies leading to certification, accreditation, and stakeholder interests. Programs, as well as individual courses, and the lessons within courses, must be aligned with certification competencies and institutional program, course, and lesson learning outcomes. The challenge we face is ensuring that the competencies are adequately addressed within and across our various programs and courses on an on-going basis. Our first use of concept mapping involved mapping competencies to clarify and validate our Information Assurance certificate program. We used CMaps (http://www.ihmc.us), a free application that supports multiple platforms and is available on the Internet, to create the concept maps. CMaps is easy to use and allows exporting to many other formats, such as for use in a presentation program like PowerPoint, or an HTML file for sharing on the Internet.

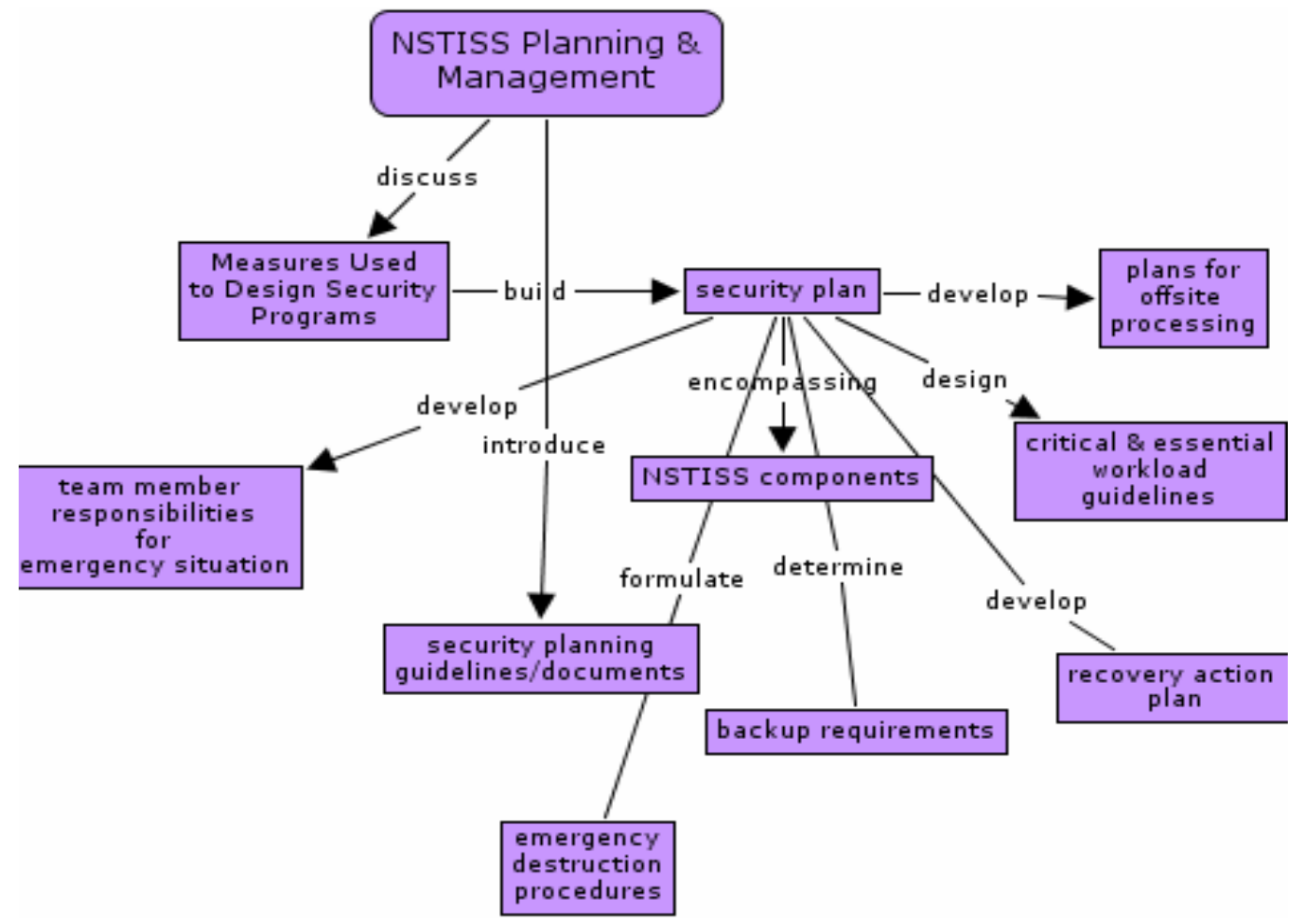

Figure Two: NCSS Standard in Planning \& Management

Beginning in 2000, the National Committee on Systems Security (NCSS) authorized the College to award an information assurance certificate in accordance with a well-articulated set of competencies to include information operations, assurance, and security in the planning and execution of national and military strategy. That authority was granted based on the College's submission of a complicated text-based representation of the alignment of courses and lessons with the NCSS competencies. Without a visual representation of the NCSS competencies and our curriculum, the alignment process was clumsy, complicated, and inefficient. In the College's most recent reapplication for the authority to award the certificate, the faculty used concept mapping tools to 
create a map for each major competency required by the National Security Agency (NSA). Figure Two illustrates a competency map of the NCSS standard in Planning \& Management. By using this map, we can see the planning and management competency requires the successful student to discuss, build, and develop (to name a few) in specific areas. The hierarchical nature of the diagram reveals that in order for students to be able to evaluate and create their own plans, they must first master certain tasks. The words connecting the tasks show what level of learning is required for that mastery.

With the competencies fully mapped, the faculty turned to the task of developing concept maps of their current courses that ostensibly satisfy those same competency requirements. The process of mapping the competencies required analysis of their levels of complexity, internal organization, and relationships. During this analysis the faculty, who served as subject matter experts, mapped the key and supporting elements of the competencies at the appropriate levels and depths. The resulting maps have become the foundation for subsequent design of new curriculum, and validation of existing curricula against the competencies. One of the concept maps resulting from this effort is shown in Figure Three.

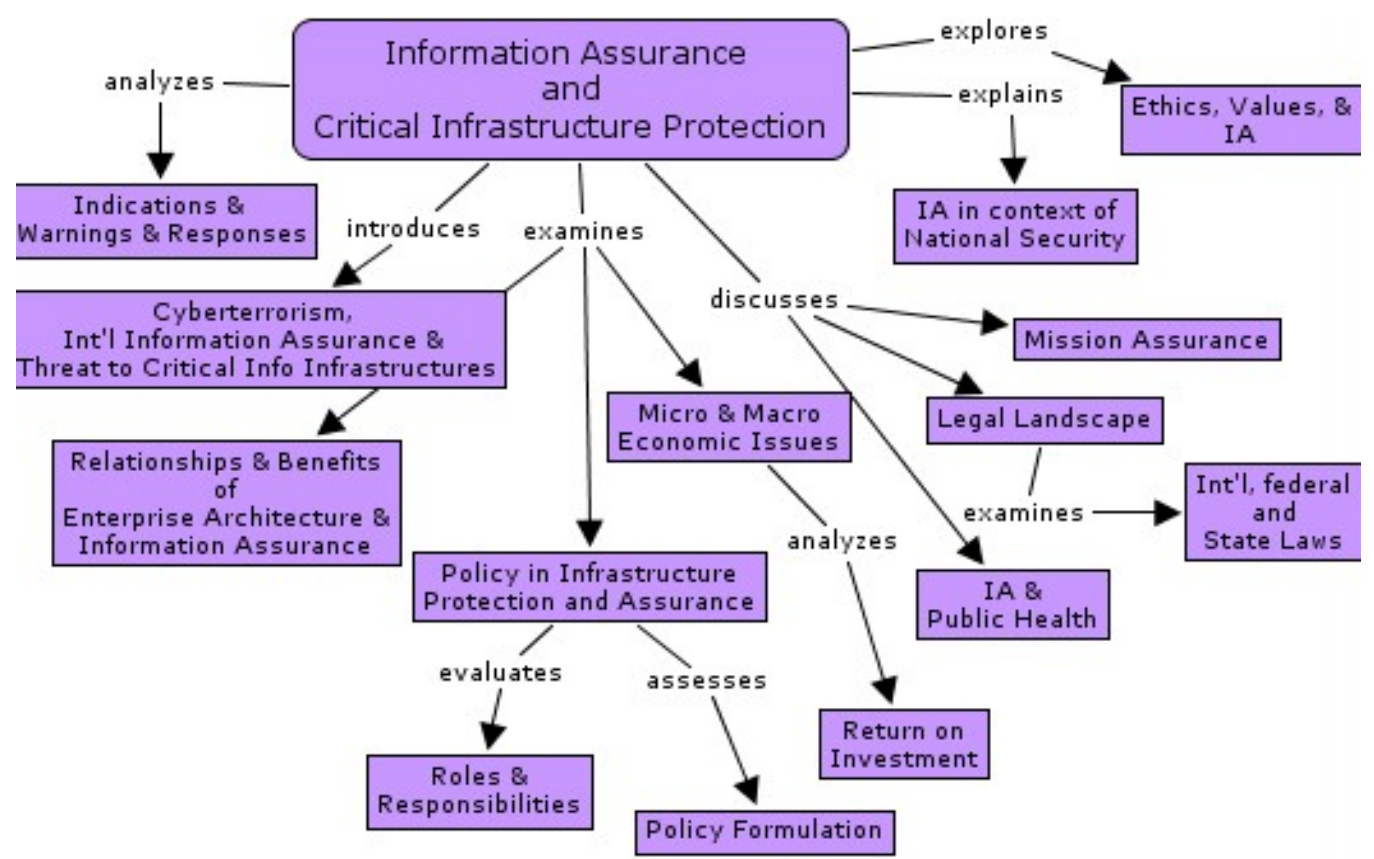

Figure Three: Information Assurance and Critical Infrastructure Protection Course

This concept map shows the content of one of the courses students are required to successfully complete for the Information Assurance Certificate, Information Assurance and Critical Infrastructure Protection (AII). After mapping their courses, faculty can then use the maps to validate their intended learning outcomes and associated content of their courses and lessons against the mapped representation of the competencies (as outlined in Figure Two). By comparing what they are teaching with the expected learning outcomes, faculty can make adjustments as required. In addition, stakeholders can readily see that the required competency areas are being taught. Because the mapping tool creates visual representation of concepts and their relationships to one another, the competencies and the curriculum can be overlaid to represent what is being taught and what must be taught. On a micro-level, we can look at the learning outcomes for each course and immediately validate if the learning outcomes are congruent with what is being taught. In Figure Three, the course lessons are represented by the "nodes" or boxes extending outward from the course. We see that this course covers material in ethics, mission assurance, the legal land- 
scape, public health, etc. As we examine each lesson and tie them together, they should bring us back to our learning outcomes. For the AII course represented here, the learning outcomes state that the students will be able to assess the strengths and weaknesses of the national strategy and determine their implications for the development and implementation of an enterprise information assurance strategy; and evaluate an enterprise infrastructure in light of information assurance laws, policies, and guidance. By mapping this one course, the Department Chairs and faculty can use the curriculum mapping tool to assist them in laying out their lessons to achieve their desired learning outcomes while College leaders can review the curriculum maps to assure quality and alignment across the curriculum. This process can be repeated for every competency area and every course. In addition, faculty may provide students with the completed maps to enhance their understanding of the educational roadmap they are expected to follow.

\section{Benefits of Curriculum Mapping}

Our experiences using concept mapping to represent the curriculum has proven beneficial to administrators and faculty. The accessibility of the graphical representation of curriculum maps facilitates validation of the degree to which the array of accreditation and certification competencies is satisfied. This unique approach to the validation process, and the relative clarity afforded by the concept maps, ensures that every competency is placed in the proper context and at the appropriate depth. The specific role that concept mapping plays in the lifecycle of the curriculum varies depending on the viewer's perspective.

Academic administrators at the Information Resources Management College are accountable for ensuring that our academic programs deliver on the student performance in the expressed competencies. In addition to managing the creation, delivery, and maintenance of the curriculum, College leaders must effectively communicate the key elements of the curriculum to stakeholders and other members of the community. First, an understanding of curriculum mapping serves as a valuable tool for administrators to guide the creation of a curriculum that crosses across several academic disciplines. The curriculum maps also serve as a framework for communicating the essence of the curriculum at varying levels, for addressing stakeholders' queries, for incorporating new competencies into existing courses, and for designing new academic programs.

Given the excellent tool that concept mapping presents as visually organizing complex material, it is a natural fit for faculty to make good use of curriculum maps to plan, develop, and implement their courses. By using curriculum mapping as a way to organize overall themes of courses and lessons, especially during the development of new courses, faculty can more comprehensively articulate the intended learning outcomes, and, they can readily see what material needs to be emphasized to scaffold learning. Curriculum mapping promotes quality in the design of new courses because major and minor ideas can be easily displayed and connections among elements can be described and organized so as to lead the development of lesson materials. In addition, mapping serves as a device to tie assessment plans to the overall structure of the course, ensuring that student learning is effectively assessed. Finally, as faculty revise courses and lessons, curriculum mapping can reveal which concepts need pruning from the map and which need additional emphasis. Curriculum mapping facilitates re-conceptualizing of course content and increases the faculty's ability to provide meaningful learning experiences for students.

Finally, from the students' perspective, the nature of intensive courses offered by the College requires that students quickly grasp the context of the courses in their program. A curriculum map, presented at the beginning of and used throughout the course of study, can promote clarity about intended outcomes of the academic program, and how the courses in the program lead to successful performance in the related competencies. For example, in the Information Assurance Certificate Program mentioned earlier, students are required to complete four courses. By giving students a visual diagram of course concepts and relationships among them, faculty provide students 
with a cognitive framework of the program and its elements that serve to scaffold their understanding of the concepts and move them from merely learning the facts of the courses to thinking critically about the network of concepts. Toward this end, the instructional approach used at the College seeks to promote active learning. Students work either individually and in teams to solve problems and analyze concepts. Professors serve as facilitators of learning, helping students to integrate ideas and learning across lessons and courses, and clarifying issues while encouraging students to formulate questions about the course materials. Concept mapping, as an idea generator that encourages students to stay on task and aids them in organizing complex problems (Coffey \& Canas, 2000), promotes active questioning and collaboration and encourages students to make connections among elements in the curriculum concept map.

\section{Conclusions}

Academic administrators, faculty, and students at the Information Resources Management College have begun using concept mapping as a tool for curriculum design and evaluation. Because concept mapping is powerful and flexible it can be applied to curriculum analysis, design, and alignment to make these processes easier to understand, discuss, maintain, and revise. These benefits have propagated across the entire spectrum of people involved in the education process. Mapping the curriculum to a significant level of specificity is also preparing the College to manage the resulting curricular materials and to use curriculum management software, a powerful set of tools for managing complex curricular materials across programs, departments, and over time. The first software designed to manage curriculum content is becoming available now in a way that it removes the barriers between managing the curriculum and delivering the educational experiences the curriculum enables. We anticipate that curriculum mapping will serve as a foundational step to manage the resulting course and lesson materials effectively. As we extend our work to map the entire curriculum at the IRM College, we will continue to collect data we can use to measure the effects of this strategy and create better tools to ensure integration between programs while abiding by directed compliance from our high-level stakeholders.

The views expressed are the authors' and do not necessarily reflect the official policy or position of the National Defense University, the Department of Defense or the U.S. Government.

\section{References}

Ausubel, D. P. (1963). The psychology of meaningful verbal learning. New York, NY: Grune and Stratton.

Ausubel, D. P. (1968). Educational psychology: A cognitive view. New York, NY: Rinehart and Winston.

Canas, A., Coffey, J., Carnot, M., Feltovich, P., Hoffman R., Feltovich, J., et al. (2003). A summary of literature pertaining to the use of concept mapping techniques and technologies for education and performance support. The Institute for Human and Machine Cognition. Retrieved November 18, 2004, from http://www.ihmc.us

Coffey, J. \& Canas, A. (2000). A learning environment organizer for asynchronous distance learning systems. The Institute for Human and Machine Cognition. Retrieved November 18, 2004, from http://www.ihmc.us/users/acanas/Publications/Leo-Iasted/Leo\%20Iasted\%20Conf.htm

Edmondson, K. M. (1995). Concept Mapping for the development of medical curricula. Journal of Research in Science Teaching, 32 (7), 777-793.

Harpaz, I., Balik, C., \& Ehrenfeld, M. (2004). Concept Mapping: An educational strategy for advancing nursing education. Nursing Forum, 39 (2), 27-30.

Hibberd, R., Jones, A., \& Morris, E. (2002). The use of Concept Mapping as a means to promote and assess knowledge acquisition. CALRG Report No. 202. 
Macnamara, J. (1982). Names for things: A study of human learning. Cambridge, MA: M.I.T. Press.

Martin, D. J. (1994). Concept Mapping as an aid to lesson planning: A longitudinal study. Journal of Elementary Science Education, 6 (2), 11-30.

Mintzes, J., Wandersee, J. \& Novak, J. (2000). Teaching science for understanding. San Diego, CA: Academic Press.

Novak, J.D. The theory underlying concept maps and how to construct them. The Institute for Human and Machine Cognition. Retrieved November 16, 2004, from http://cmap.coginst.uwf.edu

Novak, J. D. (1964). Importance of conceptual schemes for science teaching. Science Teacher, 31, 10-14.

Novak, J.D. \& Gowin, D. B. (1984). Learning how to learn. New York, NY: Cambridge University Press.

Novak, J. D. (1990). Concept maps and Vee diagrams: Two metacognitive tools for science and mathematics education. Instructional Science, 19, 29-52.

Novak, J. D. (1998). Learning, creating, and using knowledge: Concept Maps as facilitative tools in schools and corporations. Mahweh, NJ: Lawrence Erlbaum Associates.

Ruiz-Primo, M.A., \& Shavelson, R.J. (1996). Problems and issues in the use of Concept Maps in science assessment. Journal of Research in Science Teaching, 33 (6), 569-600.

Safayeni, F., Derbentseva, N., \& Canas, A.J. (2003). Concept Maps: A theoretical note on concepts and the need for cyclic concept maps. The Institute for Human and Machine Cognition. Retrieved November 18, 2004, from http://cmap.ihmc.us/Publications/ResearchPapers/Cyclic\%20Concept\%20Maps.pdf

The University of Tennessee at Chattanooga (2002). Concept Mapping and curriculum. Grayson H. Walker Teaching Resource Center. Retrieved November 18, 2004 from http://www.utc.edu/Administration/WalkerTeachingResourceCenter/FacultyDevelopment/ConceptMa pping/index.html

Vygotsky. L. S. (1978). Mind in Society. Cambridge, MA: Harvard University Press.

\section{Biographies}

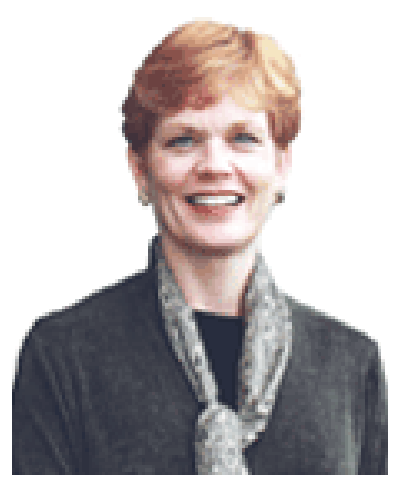

Elizabeth A. McDaniel is currently the Dean of Faculty and Academic Programs at Information Resources Management College, National Defense University. She began her academic career at the University of Hartford, and advanced to full professor, and associate vice president for academic affairs. She was an American Council on Education Fellow in the Office of the President at the University of Connecticut in 1989-1990. She served as the Executive Provost and Vice President for Academic Affairs at Nova Southeastern University from 1995 to 1998. She was a Senior Fellow at the American Council on Education in 1998 and 1999.

Dr. McDaniel holds a Ph.D. from the University of Miami, a master's degree from Barry University, and a bachelor's degree from the University of Florida. Her educational background in psychology and education underlie her commitment to teaching and learning. As a faculty member and campus leader, administrator, and scholar, she has focused on interdisciplinary education, general and liberal education, and innovation in curriculum and instruction. She is also experienced in strategic planning, multicultural and international issues, faculty collaboration, and e-learning. Her recent writing relates to new faculty roles in outcomes-based education, self-efficacy, and leadership development. Her current interests are in e-government and leadership for the information age, particularly cross-boundary leadership. 


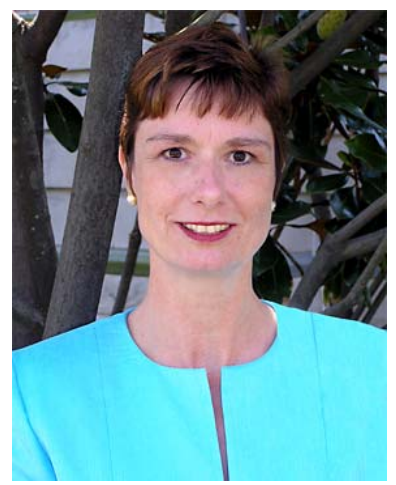

Brenda F. Roth is currently the Assistant Dean for Curriculum at the Information Resources Management College, National Defense University. She began her academic career while serving in the Air Force. She taught History at the United States Air Force Academy between 1990 and 1993, was the Chief of Curriculum Development and Integration at the Air Command and Staff College, Air University, Maxwell Air Force Base, Alabama from 1996 to 1998, and served as an Operations Officer (1998-2000) where she led a multi-service division of over 150 select field grade officers, civilian students, and international officers. Between 2000 and 2002, she was the Chief of the Professional Military Education Branch at the Pentagon. She retired from the Air Force in 2004 when she joined the staff at the IRM College.

Dr. Roth earned her Ph.D. from the University of Virginia, her master's degree from the University of Colorado at Boulder, and her bachelor's degree from the University of Arizona. As an Air Force officer, educator, and leader, her interests center on non-traditional methods of education including distributed learning, blended learning, and mastery learning. She is particularly knowledgeable about professional military education programs and policy, curriculum design and evaluation, strategic planning, and faculty development. Her current research focuses on curriculum development and innovative technology methods for improving teaching and learning.

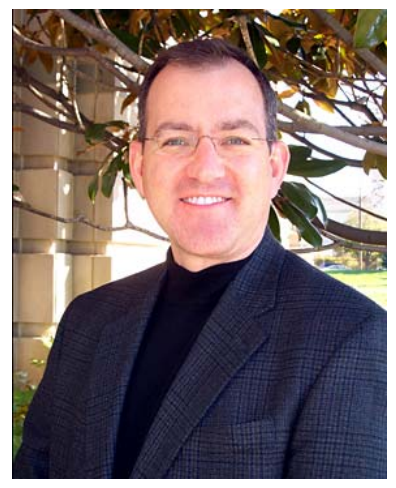

Michael S. Miller is currently the Director of the eLearning Solutions Group and the Chief Technology Officer at the Information Resources Management College, National Defense University. He manages the College's distributed learning program and an interdisciplinary group assisting the faculty with creation of teaching media for resident and distributed learning courses. His research interests include humanmachine interaction, computer-supported collaborative work, and instructional design. He served in the U.S. Army before receiving a Ph.D. in Applied Experimental Psychology from The Catholic University of America. 